\title{
Coiling of the Internal Carotid Artery is Associated with Hypertension in Patients Suspected of Stroke
}

\author{
Josephus L. M. van Rooij' on behalf of the DUST investigators · Richard A. P. Takx' ${ }^{10}$ on behalf of the DUST \\ investigators - Birgitta K. Velthuis ${ }^{1}$ on behalf of the DUST investigators - Jan Willem Dankbaar ${ }^{1}$ on behalf of \\ the DUST investigators · Pim A. de Jong' ${ }^{1}$ on behalf of the DUST investigators
}

Received: 2 September 2019 / Accepted: 14 February 2020 / Published online: 18 March 2020

(c) The Author(s) 2020

\begin{abstract}
Purpose The etiology of coiling (i.e. severe elongation) of the extracranial part of the internal carotid artery (ICA) is poorly understood with the proposed etiology being congenital, atherosclerotic or hypertension. The objective was to investigate the association of coiling with hypertension, carotid artery atherosclerosis and other cardiovascular risk factors. Methods A case control study was performed in patients suspected of stroke, with (cases) or without (controls) coiling of the ICA determined on compute tomography angiography (CTA). Baseline characteristics included age, gender, hypertension, diabetes, smoking and hypercholesterolemia. Coiling of the ICA and atherosclerotic plaque at the carotid bifurcation were assessed on CTA. Logistic regression analyses were conducted.

Results Coiling was identified in 108 patients with a median age of 71 years. Cases were compared with 256 controls with a median age of 69 years. Hypertension was present in $63 \%$ of the patients with coiling compared to $51 \%$ in the control group. Univariable analysis showed that hypertension was significantly associated with coiling, with an odds ratio of 1.65 (95\% confidence interval (CI) $1.04-2.61, p=0.034)$. Multivariable analysis corrected for age and sex resulted in an odds ratio of 1.71 (95\% CI 1.05-2.80, $p=0.032$ ), while correcting for atherosclerotic plaque at the bifurcation yielded an odds ratio of $1.63(95 \%$ CI $1.00-2.66, p=0.049)$. Age and atherosclerotic plaque were not significantly associated with coiling.

Conclusion The main finding of this study was the significant association of hypertension with coiling of the ICA and the absence of an association with age, plaques and atherosclerotic risk factors other than hypertension.
\end{abstract}

Keywords Tortuosity $\cdot$ Coiling $\cdot$ Internal carotid artery $\cdot$ Dolichoarteriopathy $\cdot$ Hypertension

\author{
Abbreviations \\ DUST Dutch Acute Stroke study \\ ICA Internal carotid artery \\ OR Odds ratio \\ rtPA recombinant tissue-type plasminogen activator
}

\section{Introduction}

Coiling (i.e. severe elongation) of the internal carotid artery (ICA) is a rare morphologic alteration in the course of the artery. The extracranial part of the ICA runs from the

Richard A. P. Takx

r.a.p.takx@umcutrecht.nl

1 Department of Radiology, University Medical Center Utrecht, Heidelberglaan 100, 3584 CX Utrecht, The Netherlands carotid bifurcation up to the entry into the petrous segment of the temporal bone [1]. The anatomical course of the extracranial part of the ICA can differ, varying from a straight course in most cases to elongation in some [1]. This elongation has been described as dolichoarteriopathy and is classified in three categories: ranging from severe (coiling), moderate (kinking) to mild (tortuosity) [1]. Coiling has been found in 3-4\% of a healthy population and has been associated with cerebrovascular insufficiency [2]. To identify associated factors the greatest contrast for power reasons between controls and the most severe dolichoarteriopathy (i.e. coiling) were introduced. Different theories have been proposed regarding the etiology of coiling. Coiling has been described as a persisting embryological state $[3,4]$, which is usually bilaterally present [5]. Advancing age may also contribute to the development of coiling through degradation and fragmentation of intramural elastin of the arterial wall [6]. Another hypothesis is that hyper- 
tension is a possible cause for the development of coiling [6]. Hypertension can lead to arterial vessel lengthening due to an imbalance between forces to the vessel wall [7]. This can result in an increase in the diameter and loss of stiffness of large arterial vessels, resulting in stretching of circumferential smooth muscle cells of the tunica media [8]. Finally, atherosclerotic remodeling could result in coiling of the arteries through hemodynamic abnormalities [9, 10]. The objective of this article is to investigate the association of coiling with hypertension, carotid atherosclerosis and other cardiovascular risk factors.

\section{Material and Methods}

\section{Study Design}

This was a retrospective analysis from data acquired for the Dutch Acute Stroke study (DUST) from the period 2009-2014 [11]. This multicenter prospective, observational study included 1393 patients who underwent computed tomography angiography (CTA) in the diagnostic work-up of a possible acute ischemic stroke. Inclusion criteria were: I) age of 18 years and older; II) the time of onset of acute neurological deficits was less than $9 \mathrm{~h}$ and III) a score of two or higher on the National Institutes of Health Stroke Scale (NIHSS) or 1 if an indication for intravenous tissue plasminogen activator (itPA) treatment was present. Exclusion criteria were a diagnosis other than ischemia on non-contrast CT scanning, renal failure or contrast allergy. Informed consent of patients or their family was obtained unless the patient had died, in which case the need for informed consent was waived. More details regarding methods and study protocol have been previously described [11]. Patients of the DUST study were selected to form a case control study, comparing a population with coiling (cases) to a random sample of patients with no coiling (controls), with a ratio of approximately 1:2. Patients with kinking or tortuosity were excluded.

\section{CT Imaging Protocol}

Images were obtained using 40-320 detector row CT scanners (Philips, Best, the Netherlands; Siemens Healthineers, Erlangen, Germany; GE Healthcare, Milwaukee, WI, USA; Toshiba, Medical Systems, Tochigi, Japan). The scan was obtained from the aortic arch to the cranium vertex. Nonionic intravenous contrast was injected $(50-70 \mathrm{ml})$ with a flow of $6 \mathrm{ml} / \mathrm{s}$ followed by saline $(40 \mathrm{ml})$ with also a flow of $6 \mathrm{ml} / \mathrm{s}$. For each patient the scan delay was calculated from time to peak arterial enhancement on CT perfusion or with contrast bolus tracking in the aortic arch [11].

\section{Assessment of Risk Factors and Atherosclerotic Plaque}

Patients characteristics were obtained at admission and included age, hypertension, diabetes mellitus, hypercholesterolemia and smoking habits. Other cardiovascular risk factors, such as body mass index and a family history of cardiovascular disease were not systematically included. The presence of atherosclerotic plaque (calcified, mixed or noncalcified) was evaluated in the left and right ICA by an experienced radiologist.

\section{Selection of Cases and Controls}

First a trained medical student under supervision of a radiologist evaluated all scans and preselected 146 cases that were suspected of coiling. In a second step these were formally evaluated according to the criteria by Metz et al. [12] and Weibel et al. [13] who described coiling as an extended elongation of the artery in a restricted space, resulting in a circular or exaggerated S-configuration of the artery (Fig. 1). This second round was done by a second trained medical student (JvR) under supervision of two radiologists (JWD, PDJ) and difficult cases were discussed in consensus.

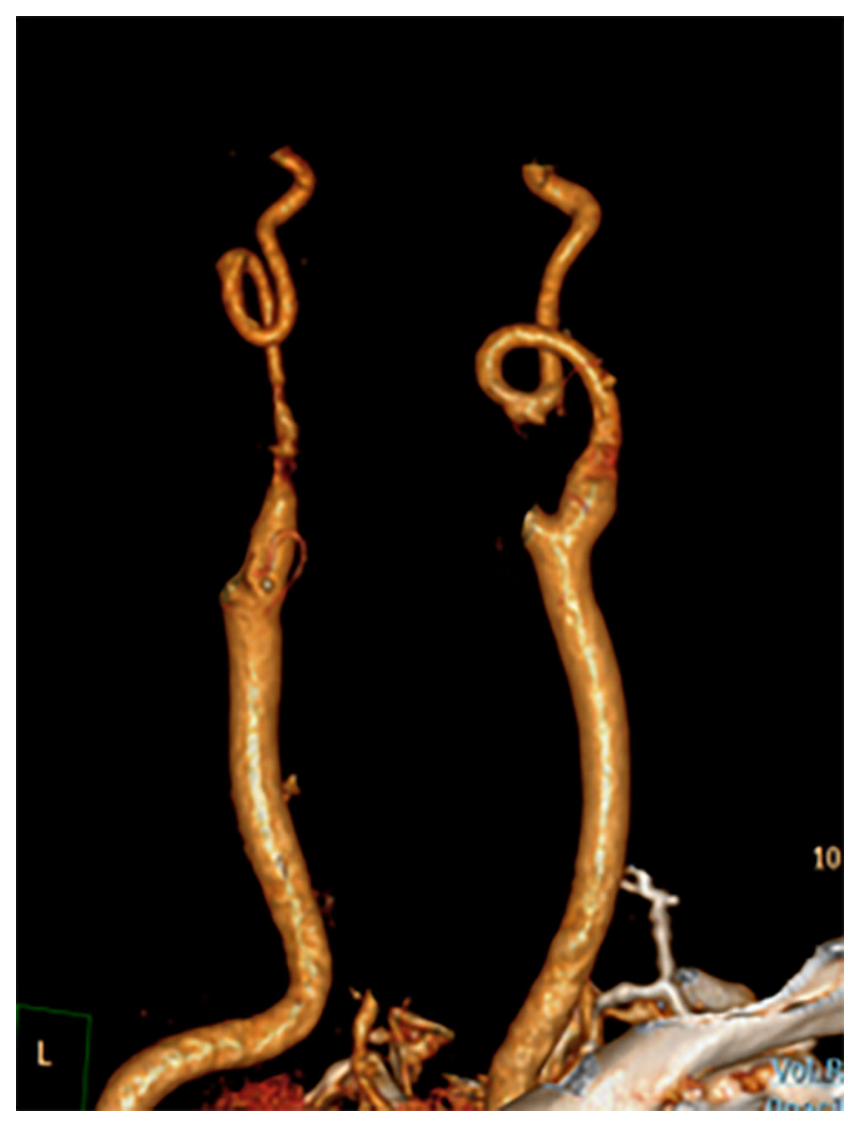

Fig. 1 3D reconstructed CT image demonstrating coiling of both internal carotid arteries in a circular configuration 


\section{Statistical Analysis}

For clinical risk factors as well as CT measures normality of the data was determined using quantile-quantile plots. Normally distributed data were reported as mean (95\% confidence interval, CI) and non-normally distributed data as median (25th percentile [P25] and 75th percentile [P75]). Binary variables were reported as frequency (percentage). Logistic regression models were used with and without the addition of potential confounders as covariates (sex and age, atherosclerotic plaque) to calculate OR and 95\% CI. A $p$-value $<0.05$ was deemed statistically significant. The SPSS random number generator was used for selection of the controls [14]. Statistical analyses were performed using SPSS version 24.0 (IBM Corp, Armonk, NY, USA).

\section{Results}

\section{Patient Selection}

Of the 146 patients who were identified as having marked elongation of the ICA, 5 scans were excluded because evaluation and $3 \mathrm{D}$ reconstruction was suboptimal due to moderate CTA image quality. Of the remaining 141 patients, 33 patients did not fulfil the coiling criteria but had kinking or tortuosity and were excluded for final analysis. This resulted in a total of 108 patients having coiling, of which 73 patients had bilateral coiling and 35 patients had unilateral coiling. Of the 296 randomly selected cases where no anomaly was observed in the preselection, 34 patients were excluded due to suboptimal evaluation/3D reconstruction. Of the remaining 262 patients, 6 scans were excluded
Table 1 Baseline characteristics of the study population in those with coiling and controls

\begin{tabular}{|c|c|c|c|}
\hline & $\begin{array}{l}\text { Coiling } \\
(n=108)\end{array}$ & $\begin{array}{l}\text { Controls } \\
(n=256)\end{array}$ & $P$-value \\
\hline $\begin{array}{l}\text { Age in years median } \\
(P 25-P 75)\end{array}$ & $\begin{array}{l}71 \\
(37-96)\end{array}$ & $\begin{array}{l}69 \\
(57-78)\end{array}$ & 0.743 \\
\hline NIHSS median (P25-P75) & $6(3-11)$ & $6(3-11)$ & 0.694 \\
\hline Female sex, $n(\%)$ & $42(39 \%)$ & $118(46 \%)$ & 0.206 \\
\hline Diabetes, $n(\%)$ & $15(14 \%)$ & $45(18 \%)$ & 0.389 \\
\hline Hypertension, $n(\%)$ & $68(63 \%)$ & $129(51 \%)$ & 0.033 \\
\hline $\begin{array}{l}\text { Hypercholesterolemia, } n \\
(\%)\end{array}$ & $39(37 \%)$ & $88(36 \%)$ & 0.767 \\
\hline Smoking, $n(\%)^{a}$ & $67(66 \%)$ & $150(65 \%)$ & 0.844 \\
\hline $\begin{array}{l}\text { Presence of atherosclerotic } \\
\text { plaque in the ICA, } n(\%)\end{array}$ & $81(76 \%)$ & $192(75 \%)$ & 0.821 \\
\hline
\end{tabular}

${ }^{\mathrm{a} C u r r e n t / p r e v i o u s ~ s m o k i n g ~}$

NIHSS National Institutes of Health Stroke Scale, ICA internal carotid artery

from the current study for having coiling, resulting in 256 controls (Fig. 2).

\section{Baseline Characteristics}

Of the patients with coiling, 39\% were female versus $46 \%$ of the patients without coiling. Median age of the cases (71 years, range 62-77 years) was comparable to the age of the control group (median age of 69 years, range 57-78 years). A history of hypertension was described in $63 \%$ of the study group and in $51 \%$ of the control group $(p=0.033)$. The groups were comparable regarding the other cardiovascular risk factors and the prevalence of plaques at the bifurcation (Table 1).

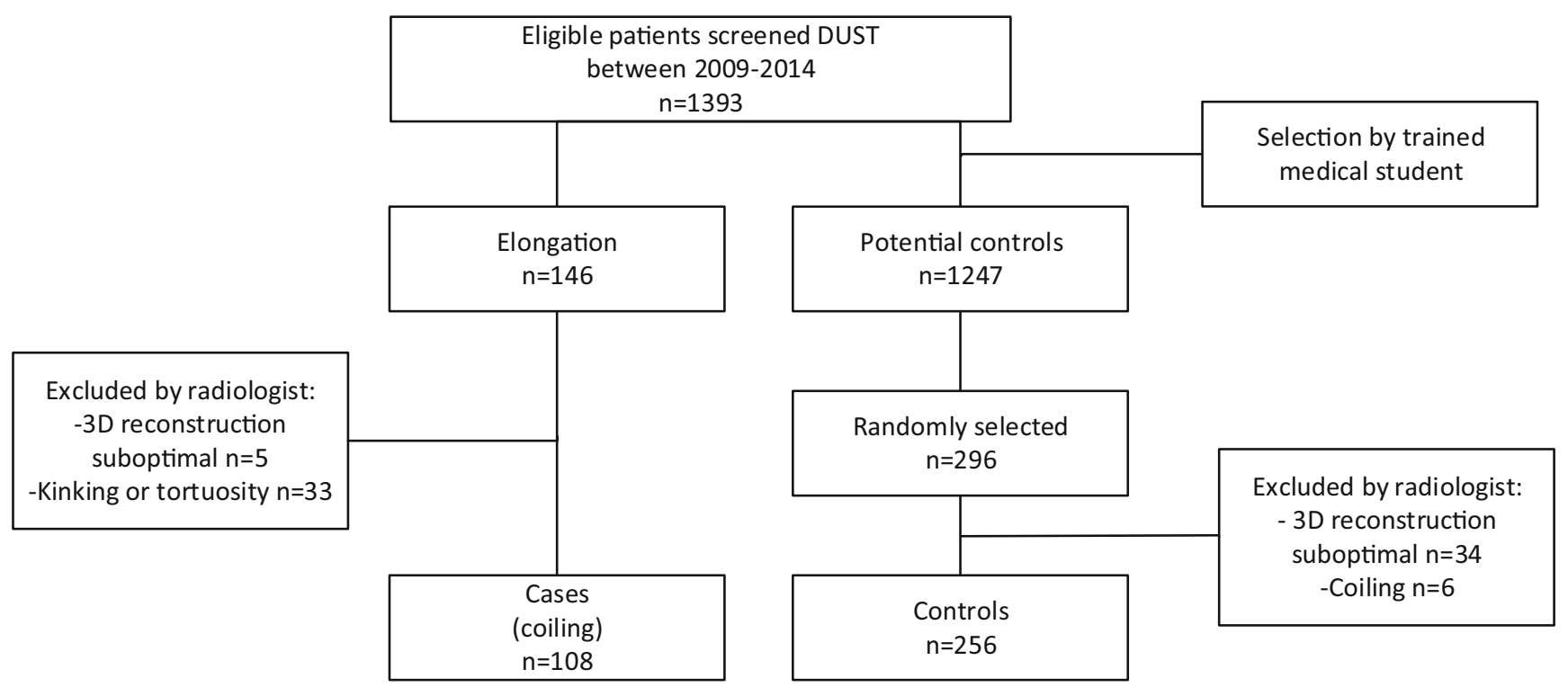

Fig. 2 Study population selection flow chart 
Table 2 Uni- and multivariable odds ratios on the association of coiling of the ICA and possible risk factors

\begin{tabular}{|c|c|c|c|c|c|c|c|c|}
\hline & Univariable & $P$-value & $\begin{array}{l}\text { Age and sex } \\
\text { corrected }\end{array}$ & $P$-value & $\begin{array}{l}\text { Atherosclerotic } \\
\text { plaque corrected }\end{array}$ & $P$-value & $\begin{array}{l}\text { Age, sex and } \\
\text { atherosclerotic plaque } \\
\text { corrected }\end{array}$ & $P$-value \\
\hline Age in years & $\begin{array}{l}1.01 \\
(0.99-1.02)\end{array}$ & 0.481 & NA & NA & $1.01(0.99-1.03)$ & 0.423 & NA & NA \\
\hline NIHSS & $\begin{array}{l}1.00 \\
(0.96-1.04)\end{array}$ & 0.941 & $\begin{array}{l}1.00 \\
(0.96-1.04)\end{array}$ & 0.904 & $1.00(0.96-1.04)$ & 0.931 & $1.00(0.96-1.04)$ & 0.954 \\
\hline Female sex & $\begin{array}{l}0.74 \\
(0.47-1.18)\end{array}$ & 0.744 & NA & NA & $0.73(0.46-1.17)$ & 0.734 & NA & NA \\
\hline Diabetes & $\begin{array}{l}0.76 \\
(0.40-1.43)\end{array}$ & 0.390 & $\begin{array}{l}0.72 \\
(0.38-1.37)\end{array}$ & 0.313 & $0.72(0.37-1.38)$ & 0.321 & $0.70(0.36-1.35)$ & 0.286 \\
\hline Hypertension & $\begin{array}{l}1.65 \\
(1.04-2.61)\end{array}$ & 0.034 & $\begin{array}{l}1.71 \\
(1.05-2.80)\end{array}$ & 0.032 & $1.63(1.00-2.66)$ & 0.049 & $1.68(1.01-2.78)$ & 0.044 \\
\hline Hypercholesterolemia & $\begin{array}{l}1.07 \\
(0.67-1.73)\end{array}$ & 0.767 & $\begin{array}{l}1.03 \\
(0.63-1.67)\end{array}$ & 0.911 & $0.99(0.61-1.62)$ & 0.974 & $0.96(0.59-1.57)$ & 0.865 \\
\hline Smoking $^{a}$ & $\begin{array}{l}1.05 \\
(0.64-1.72)\end{array}$ & 0.844 & $\begin{array}{l}1.01 \\
(0.61-1.69)\end{array}$ & 0.956 & $1.01(0.62-1.67)$ & 0.959 & $0.99(0.59-1.67)$ & 0.976 \\
\hline $\begin{array}{l}\text { Presence of } \\
\text { atherosclerotic plaque } \\
\text { in the ICA }\end{array}$ & $\begin{array}{l}1.06 \\
(0.63-1.81)\end{array}$ & 0.821 & $\begin{array}{l}0.90 \\
(0.49-1.67)\end{array}$ & 0.744 & NA & NA & NA & NA \\
\hline
\end{tabular}

${ }^{\mathrm{a}}$ Current/previous smoking

NIHSS National Institutes of Health Stroke Scale, ICA internal carotid artery, NA not applicable

\section{Odds Ratios for Having Coiling}

When comparing the group of coiling versus controls, a history of hypertension was found to be significantly associated with the presence of coiling in univariable analysis, which resulted in an OR of 1.65 (95\% CI 1.04-2.61, $p=0.034)$. Age, gender, other cardiovascular risk factors and the measured plaques were not significantly associated with the presence of coiling. Hypertension remained significantly associated with coiling after adjusting for age and sex (OR 1.71; 95\% CI 1.05-2.80, $p=0.032$ ) and after adjusting for the presence of atherosclerotic plaque at the bifurcation (OR 1.63; 95\% CI1.00-2.66, $p=0.049)$. Detailed univariable and multivariable OR are listed in Table 2.

\section{Discussion}

The main finding of this study was the significant association of hypertension with coiling of the ICA and the absence of association with age, plaques and atherosclerotic risk factors other than hypertension. These results support the hypothesis that hypertension is linked to coiling although causality cannot be concluded with certainty based on the cross-sectional data. It maybe that coiling is caused by hypertension, but it may also be that coiling is a preventive mechanism of the human body to the effects of hypertension. Hypertension is detrimental for the brain and a cause of stroke. Although, coiling maybe an advantageous mechanism to reduce the effect of hypertension on the brain.
Previous investigators showed an association between hypertension and a combined group of patients with coiling, tortuosity and kinking in smaller studies or imaging techniques that are less reliable than CT [15-17]. Although this study only included coiling, kinking and tortuosity may be due to a similar mechanism as coiling. In 1998 Del Corso et al. [9] investigated a study group of 469 patients (median age 66 years, 53\% men) using Doppler sonography in the diagnostic work-up for neurologic symptomatology or for general vascular assessment. The main outcome was that carotid abnormalities (i.e. a combined group of coiling, kinking and tortuosity) were significantly associated with hypertension in univariable analysis (52\% versus $39 \%$, $p<0.001)$. Nevertheless, no subanalysis was performed for coiling alone and no multivariable analysis was conducted to adjust for potential confounders. Pancera et al. [16] also found an association between kinking and hypertension in 590 patients $(38 \%$ versus $28 \%, p=0.02$ ) using ultrasound without multivariable adjustment. In contrast, Beigelman et al. [3], also using ultrasound and no multivariable adjustment, reported no significant association between hypertension in patients with kinking and coiling as a combined group versus patients with no elongation of the carotid arteries in 885 patients.

In the present cohort an association between either age or the presence of atherosclerosis lesions was not observed. One possible explanation for the lack of an association with age can be that the cohort consisted of older patients. The cohort was also biased towards atherosclerotic patients as they were referred for possible stroke. 
A strength of the current study is that multivariable analysis was performed while in most reports only univariable analysis was performed. Coiling was also strictly defined while others investigated a combined group of kinking, tortuosity and coiling. In addition, CTA is superior to Doppler ultrasonography used in other studies to evaluate the distal part of the extracranial carotid artery $(>4 \mathrm{~cm}$ beyond the carotid bifurcation) [18]. One main limitation of the current study is that a selected population of patients suspected for having a stroke was used. This results in a relatively high mean age of the cohort with a high incidence of hypertension and other cardiovascular risk factors. A second limitation is that in any observer study variation between readers exists and in the random controls $2 \%$ had coiling according to the observers and were exclude from the analysis. A third limitation is that controls were randomly selected and the associations may have been stronger if controls with kinking and tortuosity were also excluded. Finally, since a cross-sectional case control observational design was applied causality cannot be inferred.

\section{Conclusion}

This study demonstrated that hypertension is significantly associated with coiling of the extracranial part of the ICA. No associations were found with age, atherosclerosis and other cardiovascular risk factors. This supports the theory that hypertension is associated to this variation in carotid shape.

Acknowledgements The Dutch acute stroke study (DUST) investigators are: Academic Medical Center, Amsterdam, The Netherlands (Majoie CB, Roos YB); Catharina Hospital, Eindhoven, The Netherlands (Duijm LE, Keizer K); Erasmus Medical Center, Rotterdam, The Netherlands (van der Lugt A, Dippel DW); Gelre Hospitals, Apeldoorn, The Netherlands (Droogh-de Greve KE, Bienfait HP); Leiden University Medical Center, Leiden, The Netherlands (van Walderveen MA, Wermer MJ); Medical Center Haaglanden, The Hague, The Netherlands (Lycklama à Nijeholt GJ, Boiten J); Onze Lieve Vrouwe Gasthuis, Amsterdam, The Netherlands (Duyndam D, Kwa VI); Radboud University Nijmegen Medical Centre, Nijmegen, The Netherlands (Meijer FJ, van Dijk EJ); Rijnstate Hospital, Arnhem, The Netherlands (Kesselring FO, Hofmeijer J); St. Antonius Hospital, Nieuwegein, The Netherlands (Vos JA, Schonewille WJ); St. Elisabeth Hospital, Tilburg, The Netherlands (van Rooij WJ, de Kort PL); St. Franciscus Hospital, Rotterdam, The Netherlands (Pleiter CC, Bakker SL); VU Medical Center, Amsterdam, The Netherlands (Bot J, Visser MC); University Medical Center Utrecht, Utrecht, The Netherlands (Velthuis BK, van der Schaaf IC, Dankbaar JW, Mali WP, van Seeters T, Horsch AD, Niesten JM, Biessels GJ, Kappelle LJ, Luitse MJ, van der Graaf Y).

Funding The DUST study was supported by grants from the Netherlands Heart Foundation (grant numbers 2008 T034 and 2012 T061) and the NutsOhra Foundation (grant number 0903-012).
Conflict of interest J.L.M. van Rooij, R.A.P. Takx, B.K. Velthuis, J.W. Dankbaar, P.A. de Jong and the DUST investigators declare that they have no competing interests.

Open Access This article is licensed under a Creative Commons Attribution 4.0 International License, which permits use, sharing, adaptation, distribution and reproduction in any medium or format, as long as you give appropriate credit to the original author(s) and the source, provide a link to the Creative Commons licence, and indicate if changes were made. The images or other third party material in this article are included in the article's Creative Commons licence, unless indicated otherwise in a credit line to the material. If material is not included in the article's Creative Commons licence and your intended use is not permitted by statutory regulation or exceeds the permitted use, you will need to obtain permission directly from the copyright holder. To view a copy of this licence, visit http://creativecommons.org/licenses/by/4. $0 \%$

\section{References}

1. Yu J, Qu L, Xu B, Wang S, Li C, Xu X, et al. Current understanding of dolichoarteriopathies of the internal carotid artery: a review. Int J Med Sci. 2017;14:772-84.

2. Cioffi FA, Meduri M, Tomasello F, Bonavita V, Conforti P. Kinking and coiling of the internal carotid artery: clinical-statistical observations and surgical perspectives. J Neurosurg Sci. 1975;19:15-22.

3. Beigelman R, Izaguirre AM, Robles M, Grana DR, Ambrosio G, Milei J. Are kinking and coiling of carotid artery congenital or acquired? Angiology. 2010;61:107-12.

4. Sarkari NB, Holmes JM, Bickerstaff ER. Neurological manifestations associated with internal carotid loops and kinks in children. J Neurol Neurosurg Psychiatry. 1970;33:194-200.

5. Togay-Işikay C, Kim J, Betterman K, Andrews C, Meads D, Tesh P, et al. Carotid artery tortuosity, kinking, coiling: stroke risk factor, marker, or curiosity? Acta Neurol Belg. 2005;105:68-72.

6. Kamenskiy AV, Pipinos CJS II, MacTaggart JN, Baxter BT. Age and disease-related geometric and structural remodeling of the carotid artery. J Vasc Surg. 2015;62:1521-8.

7. Humphrey JD. Mechanisms of arterial remodeling in hypertension: coupled roles of wall shear and intramural stress. Hypertension. 2008;52:195-200.

8. Hiroki M, Miyashita K, Oda M. Tortuosity of the white matter medullary arterioles is related to the severity of hypertension. Cerebrovasc Dis. 2002;13:242-50.

9. Del Corso L, Moruzzo D, Conte B, Agelli M, Romanelli AM, Pastine F, et al. Tortuosity, kinking, and coiling of the carotid artery: expression of atherosclerosis or aging? Angiology. 1998;49:361-71.

10. Han HC. Twisted blood vessels: symptoms, etiology and biomechanical mechanisms. J Vasc Res. 2012;49:185-97.

11. van Seeters T, Biessels GJ, van der Schaaf IC, Dankbaar JW, Horsch AD, Luitse MJ, et al. Prediction of outcome in patients with suspected acute ischaemic stroke with CT perfusion and CT angiography: the Dutch acute stroke trial (DUST) study protocol. BMC Neurol. 2014;14:37.

12. Metz H, Murray-Leslie RM, Bannister RG, Bull JW, Marshall J. Kinking of the internal carotid artery. Lancet. 1961;1:424-6.

13. Weibel J, Fields WS. Tortuosity, coiling, and kinking of the internal carotid artery. I. etiology and radiographic anatomy. Neurology. 1965;15:7-18.

14. Onghena P. A theoretical and empirical comparison of mainframe, microcomputer, and pocket calculator pseudorandom number generators. Behav Res Methods Instrum Comput. 1993;25:384-95.

15. Oliviero U, Scherillo G, Casaburi C, Di Martino M, Di Gianni A, Serpico R, Fazio S, Saccà L. Prospective evaluation of hyperten- 
sive patients with carotid kinking and coiling: an ultrasonographic 7-year study. Angiology. 2003;54:169-75.

16. Pancera P, Ribul M, Presciuttini B, Lechi A. Prevalence of carotid artery kinking in 590 consecutive subjects evaluated by Echocolordoppler. Is there a correlation with arterial hypertension? J Intern Med. 2000;248:7-12.
17. Yilmaz U, Muhl-Benninghaus R, Simgen A, Reith W, Korner H. Carotid elongation does not affect angiographic results of mechanical thrombectomy in acute stroke. Clin Neuroradiol. 2016;26:183-7. 18. Nagata T, Masumoto K, Hayashi Y, Watanabe Y, Kato Y, Katou F. Three-dimensional computed tomographic analysis of variations of the carotid artery. J Craniomaxillofac Surg. 2016;44:734-42. 